\title{
Disciplines, Sectors, Motivations and Power Relations in Forest Landscape Restoration ${ }^{\circ}$ a
}

\author{
Stephanie Mansourian
}

\begin{abstract}
Understanding the diversity of stakeholders involved in large scale forest restoration is essential to its success as restoration is fundamentally about people. Stakeholders may be categorized in different ways, recognizing that categories hide unique differences. When dealing with landscapes or large scales, stakeholders can be found at different spatial scales, and those involved in the restoration action may not necessarily be the ones benefitting or losing the most from restoration. In forest landscape restoration (FLR), each stakeholder may understand the approach differently, engage with it in diverse ways, be motivated by different benefits and may use it for different outcomes. The purpose of this contribution is to better understand how different stakeholders in FLR can be categorized and what motivates them to engage in restoration. Power dynamics among stakeholders shape decision-making related to large scale forest restoration but are often overlooked. Exploring some of the contextual specificities of FLR initiatives helps to define the range of issues associated with such dynamics among stakeholders. I propose to disaggregate 'stakeholder engagement' focusing on five dimensions to better understand the different stakeholders engaged in FLR, and then apply it to one case study in Madagascar. Such an approach can support policymakers, project developers and managers, as well as other decisionmakers in designing more effective FLR interventions.
\end{abstract}

Keywords: engagement, FLR, governance, motivation, stakeholders

\section{\$) Restoration Recap \&}

- The long-term viability of forest landscape restoration projects may be jeopardized without effective identification, understanding, and engagement of stakeholders.

- Understanding these divergences and the motivations of different disciplinary stakeholders can help to design more effective FLR strategies.
- Globally, improved processes, systems, and capacity are required to ensure that all stakeholders are effectively brought into FLR processes, can play a role (where relevant) in the FLR decision-making process, and when necessary receive fair compensation.
Fain orest landscape restoration (FLR) has become a popular approach to tackling deforestation and forest degradation (Besseau et al. 2018, ITTO 2020). It was defined in 2000 by 30 experts convened by the World Wide Fund for Nature (WWF) and the International Union for Conservation of Nature (IUCN) with the specificity that it is

Color version of this article is available through online subscription at: http://er.uwpress.org

(2) This open access article is distributed under the terms of the CC-BYNC-ND license (http://creativecommons.org/licenses/by-nc-nd/3.0) and is freely available online at: http://er.uwpress.org

Ecological Restoration Vol. 39, Nos. 1-2, 2021

ISSN 1522-4740 E-ISSN 1543-4079

(O2021 by the Board of Regents of the University of Wisconsin System. a long-term process to return forest quality and quantity in landscapes while meeting both human and ecological objectives (WWF and IUCN 2000). A first step in, and indeed a principle of, FLR implementation is stakeholder engagement (Vallauri et al. 2005, Stanturf et al. 2017, Besseau et al. 2018). Höhl et al. (2020) refer to "the importance of local stakeholder involvement" being a recurring theme in their analysis of successes and failures in FLR. Nevertheless, stakeholder engagement frequently does not happen, or happens in a superficial or inappropriate manner (Murcia et al. 2016, van Oosten et al. 2019). Truly and effectively engaging stakeholders takes time, and FLR projects are often time-constrained because of donor funding and other factors. Yet the long-term viability of FLR, and support for restoration projects more generally, may be jeopardized without effective identification, 


\section{Understanding stakeholders}

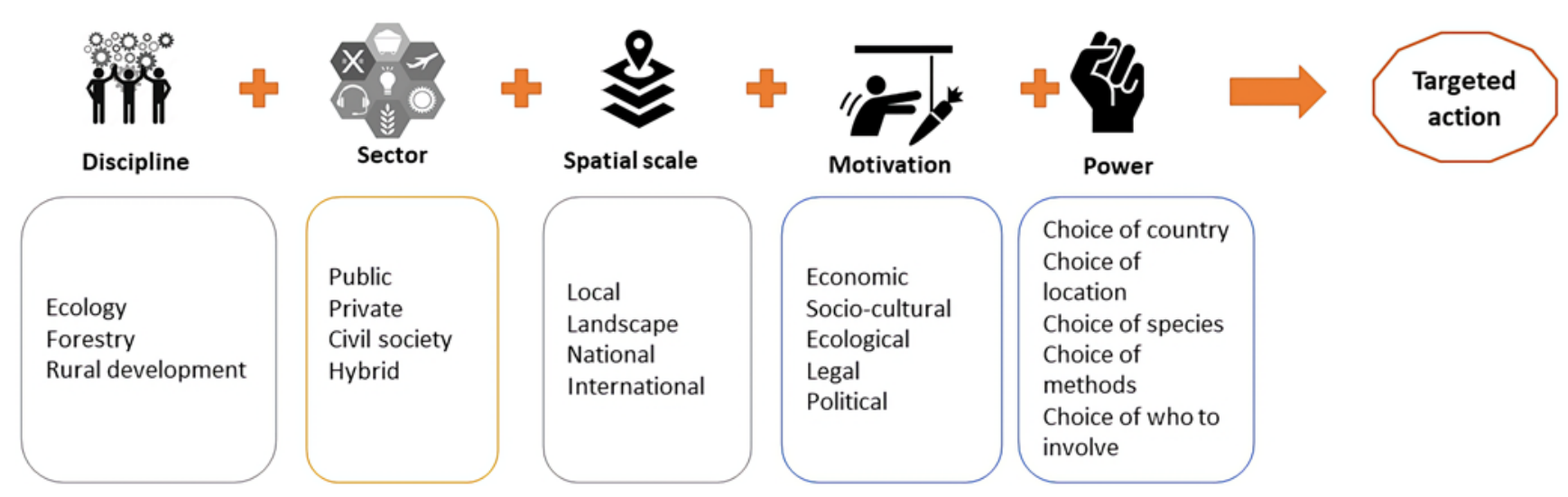

Figure 1. Overview of stakeholders, their motivations and power dynamics in FLR.

understanding, and engagement of stakeholders (Reed et al. 2009, Ciccarese et al. 2012). To successfully engage stakeholders in FLR requires a refined understanding of what motivates them. This contribution aims to provide insights into understanding stakeholders to better engage them and design more effective FLR interventions. It draws on the stakeholder literature, FLR project experiences, and uses one FLR project to illustrate how an understanding of stakeholders leads to the design of targeted project actions.

Freeman (1984) defines stakeholders as "any group or individual who can affect or is affected by the achievement of the organization's objectives". In the context of FLR, stakeholders are those who are impacted by restoration, who carry out restoration, who benefit or lose from it, who shape it, and who influence the course it takes. As restoration scales up, as in FLR, a larger number and diversity of stakeholders appear; as a result, there are more power issues, potential conflicts, and trade-offs (Sayer et al. 2015, Reed et al. 2016).

Stakeholders in FLR may be categorized in different ways: they may be affected by an FLR initiative or affect it (Nutt and Backoff 1992, Mathur et al. 2007), they may have the power to influence (Krott et al. 2014) or have a legitimate interest in the project (El-Gohary et al. 2006), they may be rightsholders or resource providers. Furthermore, they may be informed, consulted, co-producers of knowledge or empowered (Enengel et al. 2012). Stakeholders may also have an urgency of claim on the object (Mitchell et al. 1997). In the context of FLR, for example, these powers may be held by governments who can influence land use and assert legitimate authority, but equally by local communities who may also assert authority and claims over land and forests.

I posit that to take effective actions in FLR requires a more refined understanding of stakeholders. To do this, I propose to disaggregate "engaging stakeholders" into at least five dimensions that can improve this process of engagement (and which can be refined on a case by case basis). These dimensions are: 1 . understanding the sector and; 2 . the discipline that shape stakeholders' relationship to the forest and landscape; 3. the spatial scale within which they operate (from local to international); 4. the possible motivations driving their desire to engage in FLR or not, and finally; 5 . the power dynamics affecting their engagement to the FLR process and to others engaged within that process (which are themselves shaped by the first four dimensions-Figure 1). This is not intended to be an exhaustive approach to understanding stakeholders in FLR, but rather a first step in that direction as this is an area urgently requiring further research. Whereas others (e.g., Buckingham et al. 2018) have focused on tools to identify stakeholders or on defining stakeholders in a particular context (e.g., Hagger et al. 2017), I focus on understanding what might drive stakeholders to engage or not in restoration. This requires understanding and qualifying stakeholders in a much more detailed manner than is currently happening.

To illustrate the dimensions proposed here, I use one case that has been comprehensively analyzed and documented, the Fandriana-Marolambo FLR project in Madagascar (Mansourian et al. 2016, Mansourian et al. 2018, Stanturf et al. 2020). This project was initiated by WWF in 2003 and spanned 13 years. It was designed from the outset as an FLR project to improve both the living conditions of those in the landscape, and to improve biodiversity conservation through FLR. The landscape extends 203,080 hectares (ha) and is inhabited by about 150,000 people from three different ethnic groups that practice subsistence farming. An area of dense moist evergreen forest $(95,063 \mathrm{ha})$, gazetted as the Marolambo National Park in 2013, lies at the core of the landscape. The rest of the landscape is a mosaic of plantations, savanna, and agricultural crops (Roelens et al. 
2010). Under the FLR project, WWF staff worked with communities and local authorities and associations to carry out a series of activities in the landscape, including: agreeing on a joint vision for the landscape, clarifying land status and tenure, integrating FLR within local development plans, strengthening local associations, introducing alternative livelihood activities (such as improved rice cultivation, beekeeping and production of essential oils), active and passive restoration, support to local communities to strengthen their skills, identifying new financing options, and transferring management rights to local community associations (Mansourian et al. 2018). Activities evolved over the course of the project's four phases to respond to both donor demands and the reality on the ground shaped by local stakeholders. Overall, 100 communities engaged in the project, carrying out both active and passive restoration on 6,786 ha within specific zones in the wider landscape (Mansourian et al. 2018). Farmers and other community members were trained in diverse skills, including how to grow fruit trees and other improved agricultural methods. Elders and notables played an important role in the project helping to insert it into community and regional development plans.

In the next sections I first identify the reasons to carry out the disaggregation of "stakeholder engagement", then present the five dimensions of stakeholder engagement (Figure 1). In the final section, I illustrate this by applying it to the Fandriana-Marolambo case.

\section{Why Understand Stakeholders in FLR?}

Researchers and practitioners in FLR have recently identified the need to "engage stakeholders" (Besseau et al. 2018), to "prioritize local stakeholders" (Erbaugh et al. 2020) or to determine the impacts of FLR on stakeholders (Adams et al. 2016). Most available guidance on FLR refers to "stakeholder engagement" (Vallauri et al. 2005, Stanturf et al. 2017, Besseau et al. 2018). In practice, to engage stakeholders it is essential to understand what shapes the way they relate to the forests, the land, and to each other in the context of a land-modifying approach such as FLR. I highlight three main reasons here for which understanding stakeholders in FLR is essential. First, within larger scales such as landscapes, diverse stakeholders overlap with different objectives, and trade-offs are necessary (Sayer et al. 2008 ). For a project manager, donor or policymaker to manage these trade-offs, it is useful to understand these motivations and power dynamics in order to identify relevant leverage points and remedial actions. Second, if actions that engage different stakeholders are to be effective, they need to respond to the potential motivations of these stakeholders. Without an understanding of the motivation of stakeholders, it is difficult to define appropriate and relevant actions for FLR. Third, with a view to ensuring long term sustainability of FLR interventions, it is useful to be responsive to personal motivations and power dynamics that may evolve over time as these will determine the long term success of FLR actions in the landscape.

Therefore, it is useful to attempt some level of categorization of stakeholders involved in FLR, recognizing the need to dig deeper in individual cases to understand the nuances (e.g., within individual households) that ultimately influence how they approach FLR. Indeed, social diversity may exist even within groups of stakeholders. For instance, young women within communities may have very different motivations than those of older male community members (Blom et al. 2010).

\section{Understanding Stakeholders in FLR}

Stakeholders can be characterized in several ways, for example according to disciplines, sectors, spatial scale, or role in the degradation/restoration continuum, or as winners or losers, proximate or distant stakeholders (Grimble and Wellard 1997). None of these categories are static, as individuals may move from one to the other over time or may simultaneously belong to more than one category. These categories shape their relationship to the forest and land and ultimately to FLR interventions. Five dimensions are presented in this section.

\section{Scientific Disciplines, Communities of Practice as Stakeholder}

In a recent analysis, three broad scientific disciplines and communities of practice were found to have a vested interest in FLR: the ecology community, the forestry community, and the rural development community (Mansourian 2018a). Within these, further sub-categories can be identified, such as landscape ecology and restoration ecology under the broader ecology community. Subsequently, communities of practice that play an important role in conducting relevant research, in leading FLR projects and in shaping approaches and policies, hold different discourses on FLR (Reinecke and Blum 2018).

The definition of FLR originated in the year 2000 in the ecology community (WWF and IUCN 2000). It built on concepts from landscape ecology, restoration ecology and conservation biology, whilst also recognizing the need to address stakeholders' needs. For restoration ecologists, the primary purpose of FLR is to aim for full recovery of the ecosystem consistent with the "reference" model (Gann et al. 2019). For the forestry community, forest restoration is one of many management tools available to establish a functional forest that fulfils different roles or functions in the overall ecosystem (Stanturf et al. 2014). Although a tendency to use only a handful of tree species has characterized the sector (O'Farrell and Anderson 2010, 
Boedhihartono and Sayer 2012), many countries, such as the US and Switzerland, promote multiple use forests (rather than focusing simply on timber production) or close to nature forestry (seeking to mimic natural processes insofar as possible). For the rural development community, the role of forests and FLR in sustaining livelihoods is increasingly recognized (e.g., IPBES 2018). Community forestry has been promoted for decades in many countries, and community-based forest management is seen as an effective tool to meet the twin goals of improving livelihoods of rural communities and improving forest management practices (Charnley and Poe 2007). The rural development community has been a long-term player in land transformation, including different forms of forest restoration and rehabilitation in landscapes (e.g., Poffenberger 2006, Nagendra 2007). For example, many agroforestry projects were initiated under rural development schemes, as were fuelwood plantations established to reduce impact on forests to allow them to recover and regenerate. These initiatives support restoration of forested landscapes as well as improving local livelihoods.

Having diverse disciplines develop evidence and theory about FLR brings tremendous value to this relatively new discipline. However, the fact that these often operate in independent silos reduces the effectiveness of their contribution to the practice of FLR (Carmenta and Vira 2018) and raises several challenges such as misunderstandings over terms used or competition for funding. Collaborations may be impeded by fundamentally different approaches despite the use of common terms. Understanding these divergences and the motivation of different disciplinary stakeholders can help to bring different groups together and seek common ground to reduce competition and enhance cost- (and time-) effective collaboration while making trade-offs explicit.

\section{Sectoral Stakeholders}

The role of different sectoral groups in driving FLR initiatives has an impact on the intervention's credibility, sustainability, reliability, and funding. Many of the recent statements driving FLR come from public sector actors or international private actors (e.g., the recent World Economic Forum announcement of the "1 trillion trees" initiative). Improving linkages between these higher-level ambitions and local realities is a first step to their sustainability (Chazdon et al. 2017). Embedding FLR concepts within the practices of the private sector or a government initiative can ensure its durability. This may be done for instance, by including FLR as an approach eligible for government subsidies.

Groups of sectors involved in FLR may be classified as public, private, civil society, or hybrid (Agrawal and Lemos 2007). Within each group, specific sectors may be identified such as the mining, agriculture, or forestry sector.

\section{Public Sector}

Governments worldwide have embraced FLR, particularly since the 2011 Bonn Challenge on FLR launch (Besseau et al. 2018) which provided a platform to profile national commitments on FLR. All three Rio conventions refer to restoration and 62 governments have committed (at the time of writing) to restoring large areas under the Bonn Challenge on FLR, although in practice different government ministries and sectors deal with each convention (Akhtar-Schuster et al. 2017). Whilst there are increasing calls to bridge sectors, and to integrate better across ministries as well as to "break down silos", governments continue to function the world over within sectoral boundaries. Government departments or ministries often conflict and rarely collaborate towards the same restoration objectives (van Oosten et al. 2018). For example, typically, agricultural subsidies provided by the Ministry of Agriculture and the restoration priorities of the Ministry of Environment clash (Carmenta and Vira 2018, Schweizer et al. 2019). Furthermore, the complexity of policies and regulations produced by different departments may complicate FLR implementation (e.g., McGinley et al. 2012).

\section{Private Sector}

The private sector has an interest in FLR at different levels. Large private companies may need to consider restoration in their "license to operate". For example, within the forestry sector, restoration is included in schemes such as the Forest Stewardship Council (FSC) or other forest management certification and labeling schemes (Ciccarese et al. 2012). Mining companies and others involved in natural resource extraction or management have legal obligations to restore some areas of forest (Clewell and Aronson 2006). Other sectors such as the insurance sector are increasingly seeing the benefits of promoting "natural infrastructure" to reduce or mitigate the impacts of climate change and other natural disasters (SwissRe 2016). Recent research on the potential of forests to mitigate these impacts are likely to further increase such interest by the private sector (Bastin et al. 2019, Brancalion et al. 2019). At a smaller scale, private landowners may be required by law to maintain forest areas for example to protect watercourses or they may be encouraged to do so through payments for ecosystem services as has been the case for example in China under the 'Grain for Green' program (Liu et al. 2008).

\section{Civil Society}

For local communities living in the landscape, land transformation measures such as FLR or restoration more broadly, has possibly the most significant impacts. Frequently because of their dependence on natural resources (e.g., for food, medicines, building materials, spiritual healing, etc.), rural resource-dependent communities have the most to gain or lose from FLR (Erbaugh et al. 2020). FLR 
initiatives led by communities are more likely to succeed in the long term as this group of stakeholders are closest to the forest and land (Höhl et al. 2020). By taking their needs into account, FLR may help increase and sustain the valuable goods and services that they require from forests. For example, farmer-managed natural regeneration being promoted in West Africa (Kandel et al. 2021), helps to reconcile food production with soil conservation and biodiversity priorities (Weston et al. 2015). However, when FLR does not take these needs sufficiently into consideration, it can lead to conflict, exacerbate inequalities, and negatively affect livelihoods (Adams et al. 2016). "Elite capture" (when a privileged group derives the majority of benefits) has been highlighted as problematic in FLR and related large-scale restoration initiatives (Rai et al. 2018, van Oosten et al. 2019). Although there is minimal research in the peer reviewed literature, local, self-organized, community-level restoration processes also exist, although these are often not labelled FLR by the mainstream literature (e.g., Poffenberger 2006). Such initiatives deserve to be examined as their roots in local knowledge of ecosystems may prove invaluable in the context of FLR (Lake et al. 2018).

\section{Hybrid}

Several groups of stakeholders can come together under hybrid arrangements. Such governance arrangements are recognized as increasingly relevant to our globalized world (Agrawal and Lemos, 2007). They recognize the unique role of each stakeholder or stakeholder group (Ros-Tonen et al. 2014). Hybrid arrangements are particularly important in FLR where a diversity of stakeholders from different spatial scales engage in the process. In the Fandriana-Marolambo case, communities, local associations, WWF, Madagascar National Parks, the Forest Service and local authorities were all active participants in the FLR process (Mansourian et al. 2016).

\section{Stakeholders at Different Spatial Scales}

FLR takes place within the fuzzy framework of "landscapes", and the defined or undefined perimeter of the landscape reflects power tensions. Such a space is ridden with questions such as: Who defines the landscape boundary? Who is in and who is out? Furthermore, although the landscape may be the focal space, interactions with higher and lower spatial scales are important (Cash et al. 2006, Kozar et al. 2014, Ekroos et al. 2017, Mansourian and Parrotta 2019) and an understanding of these scales, and of relevant stakeholders at each, is necessary to determine who to take into account, and who to engage and how (Buckingham et al. 2018).

Typically, FLR interventions may focus on a particular scale (e.g., national) when in fact different interventions with diverse stakeholder groups at multiple scales may need to be part of the overall FLR package and coordinated as such. Stakeholders that are situated at different spatial scales may also move between scales over time (Cash et al. 2006). While non-governmental organizations may act locally, depending on their donors, they may reflect the agenda of a foreign government.

At an international scale, the Bonn Challenge has been a means of promoting an international political FLR movement (Besseau et al. 2018). International organizations, such as WWF for example, work across scales, with an international agenda complemented in many countries by a local office that may work closely with national and local actors and partners. Research is also beginning to demonstrate how decisions taken at one national scale (e.g., decentralized government) may not be matched by funding for FLR which may take place at another jurisdictional scale (e.g., national government) (e.g., Wiegant et al. 2020). Equally, at a local level, community associations play an important role as they may have the power to disrupt implementation of an FLR initiative if they wish to do so and alternatively, to support it (Erbaugh et al. 2020). Rarely are local communities prioritized in decisions on FLR.

Inconsistencies across scales, or poor attention to key influences from different scales may negatively impact on FLR in the landscape. For example, Wiegant et al. (2020) found that in Ecuador, while funding for FLR was going to one level of government, the decentralized government level that needed to carry out the FLR activities was not receiving these funds. Flexibility in collaboration across levels is needed for effective FLR implementation. Polycentric governance acknowledges the roles of multi-scalar actors and provides a realistic approach to FLR decisionmaking (e.g., Ostrom 2010, Bixler et al. 2018).

\section{Motivations of Stakeholders}

Stakeholders may hold a stake in the FLR process for different reasons. Clewell and Aronson (2006) identified five rationales to carry out ecosystem restoration: technocratic, biotic, heuristic, idealistic, and pragmatic. These may be re-categorized in the context of the dimensions of sustainable development under the broader headings of economic, socio-cultural, ecological, legal, and political (Mansourian 2018b; Figure 1). Motivations vary by stakeholder type and by region (Hagger et al. 2017) and include complying with legislation; improving soil, water, and land; seeking to diversify available food or NTFPs; or to restore land for cultural or spiritual reasons. For example, in Ethiopia numerous religious forests have been established around Coptic churches (Ruelle et al. 2017). Complying with legislation is frequently a motivation for both large and small economic actors (e.g., Aronson et al. 2011). The challenge with FLR is that at any point in time, within larger scales, different stakeholders will be motivated by different aspects. An international donor will have a different motivation to a local NGO or a local farmer in engaging in FLR. 
Understanding the motivation of different stakeholders helps to design projects with multiple stakeholders that can contribute to their different priorities. For example, in Madagascar, WWF's FLR program sought to balance both ecological needs by planting indigenous species and the needs of the local population by supporting the planting of fast-growing tree species for fuelwood and fruit trees for food (Mansourian et al. 2018). Understanding different motivations is also a starting point for the necessary negotiations when tackling inevitable trade-offs among different stakeholders (Boedhihartono and Sayer 2012). Different motivations also signify potential conflicts which may lead to FLR actions being purposefully destroyed, for example through fire.

Economic motivations for restoration include contribution to a company's corporate social responsibility, financial (or other) compensation for local communities, reducing risk (at different levels-for companies, but also for local communities), and direct funding for restoration. Increasingly, companies are voluntarily engaging in tree planting typically to contribute to improving their image in response to customer and shareholder pressure. Restoration can be seen by consumers as generating positive impacts, such as through offsetting carbon emissions from company activities. Tree planting under these conditions often pays little to no attention to social or ecological measures and long-term impacts (Bäckstrand and Lövbrand 2006) and concerns over greenwashing and the real impact of such initiatives have been raised.

Socio-cultural motivations include traditions, the spiritual value of forests, heritage, identity, recreation, aesthetic values, and traditional practices, among others. Several documented (and probably many more undocumented) cases of FLR are led by indigenous and local communities around the world (Lake et al. 2018). Many of these traditions have been passed from generation to generation. For example, in the Atlas Mountains of Morocco traditional pastoral systems called "aqdals" set aside land to naturally regenerate (Auclair et al. 2006). In addition to the practices themselves, the selection of tree species is also often based on traditional knowledge. For example, Native Americans in the western USA have managed fire adapted tree species for centuries. However, post-colonial interventions have modified this delicate balance, leading oftentimes to highly flammable forests and resultant massive fires (Lake et al. 2018).

Ecological motivations are multiple and include erosion control, pollination, water quality, soil conservation, species habitat, reproduction sites, migration routes, and feeding areas for rare or endangered species, among others (Mansourian and Vallauri 2014). Environmental non-governmental organizations (NGOs) have led efforts on FLR. They have increasingly seen it as complementary to other conservation measures such as protected areas. As ongoing research highlights, amid the dual climate and biodiversity crises our planet is facing, ecologists (environmental NGOs, researchers, individuals, environmental ministries etc.) are inevitably having to consider restoration as a fundamental tool to achieve their objectives. With habitat loss the single highest cause of species extinction (Brooks et al. 2002, Crouzeilles et al. 2016), protecting areas is no longer sufficient and restoration is becoming essential. International NGOs such as WWF, The Nature Conservancy (TNC) or the World Resources Institute (WRI), but also local NGOs, are actively promoting FLR and large-scale restoration. Interventions are frequently project-based and as such may be short term (associated with short-term donor funding) with limited impact on long term processes such as FLR. In a broader critique, Adams et al. (2014) raise the question of the legitimacy of unelected (foreign) environmental NGOs intervening in countries to change and shape land use, notably through restoration.

Legal and political motivations for restoration include commitments under global agreements, policy/legislation, and tenure rights, among others. Companies, particularly in the extractive sector, are generally required by law to compensate or remediate their activities through some form of rehabilitation or restoration. Other legal requirements exist to maintain or return a certain area (e.g., along water courses) under forest. For example, the Brazilian pulp company Fibria has committed to restoring 20,000 ha in the Atlantic Forest. At the same time, private landowners are required by law to maintain at least $20 \%$ of their land under forest (Pinto et al. 2014, Kröger 2017).

Funding from international donors (public or philanthropic) exerts an influence on FLR implementation and related land use, policies, development, and more broadly international cooperation (Lerch 2014). For example, the Arcadia Fund in the UK has played an important role in shaping the Endangered Landscapes Programme which focuses on restoring landscapes in the UK. Public bilateral donors may be motivated to advance their country's commitments under different conventions (e.g., the three Rio Conventions). They may also be keen to exert an influence in different countries' land sectors, seen as harboring critical commodities (Lerch, 2014). Also, they may be seeking to promote their own industry (e.g., forestry) abroad.

National governments in turn may choose to invest in FLR for many reasons: FLR may be seen as a way of improving ecosystems, land and soil quality, or of improving biodiversity conservation, notably in line with commitments under the Convention on Biological Diversity (CBD). FLR may also be used as a covert strategy to displace local people from their lands or to nationalize land or forests (Rai et al. 2018). For example, native tree use in restoration programs often translates in re-appropriation of land by the government since in many countries (e.g., Madagascar), such native forests are public by law. In contrast, farmers or communities may establish productive plantations of exotic trees to take over land (Lund 2011). 


\section{Power Dynamics and FLR}

Decisions around restoring landscapes are wrought with power imbalances. Power can be defined as a social relationship between two actors where one group has the ability to affect or modify the behavior of the other. Past restoration and reforestation efforts have shown the need to question assumptions that restoration is for the good of all. It is apparent that power dynamics come into play in FLR and other large-scale tree planting interventions and may increase the marginalization and vulnerability of certain stakeholders (e.g., McElwee 2009). Yet, questions such as who decides what to restore and where, versus who has to accept those choices are rarely considered in practice. I highlight five specific choices in FLR that have implication for power dynamics:

1) Choice of country: The selection of target countries that receive funding from large donors such as the Global Environment Facility (GEF), or the Green Climate Fund (GCF) are often based on political preferences and priorities (Lerch 2014) that have little to do with real needs for FLR and may result in an unequal geographic distribution of funding for restoration programs. "Dominant" or unverified information (Krott et al. 2014) has been used through diverse global maps for FLR that do not always reflect local needs and realities (e.g., Veldman et al. 2015). 2) Choice of location: Within a country, landscapes may be selected for FLR not because they need restoration but for other reasons. For example, a location may be selected for restoration with the unstated aim to displace ethnic minorities (Virapongse 2017). Green grabbing by environmental groups, or land grabbing by companies or the government under the guise of FLR (Zoomers 2010) is a form of coercion, a key element of power (Krott et al. 2014). 3) Choice of species: Tree species may be selected by the forest service that do not reflect the needs and priorities of those living in the landscape (e.g., McElwee 2009). Incentives or disincentives used to alter the behavior of the subordinate (in this case, planting trees of different species) reflect power imbalances (Krott et al. 2014). 4) Choice of methods-Methods selected for restoration may not be those most relevant to the site, or to traditional local practices (Lake et al. 2018). 5) Choice of stakeholders to involve (or not)-Stakeholder engagement exercises are often flawed and superficial (Rai et al. 2018).

In turn, the power imbalances stemming from these choices can lead to three inter-related impacts. The risk of marginalization-FLR may exacerbate vulnerabilities or lead to poor communities being marginalized as their rights to land and autonomy may be affected by FLR initiatives (Rai et al. 2018). Concerns have been voiced about the potential risk of related interventions under REDD+ that could lead to the removal of communities from their land so as to control and secure the long-term sequestration of carbon promoted under these schemes (e.g., Phelps et al.
2010, Zoomers 2010). Similar risks exist with FLR; “elite capture" in many conservation (and restoration) projects has been long documented (e.g., Nagendra 2007).

Opportunity cost of FLR-FLR is a long-term process and as such, land that is placed under restoration, depending on the intervention and approach selected, may be unavailable for other uses for several years or decades. Where this takes place on private land, with the informed consent of landowners, it may not be an issue, but all too often, it takes place either on public land or on communal, contested, or untitled land (Verdone and Seidl 2017). Economic arguments may lead to decisions that appear financially viable in the short term but disregard the needs of those closest to the landscape, and often those that are most vulnerable.

Distributional aspects (across space and time)-While some groups may be empowered by restoration (e.g., the forest service may take over control of land to implement a REDD+ project [Phelps et al. 2010]), others-often those already poor and marginalized-may find their claims weakened. Distributional aspects are often not considered, with overall gains to "society" appearing as positive, at the expense of local communities (Cronkleton et al. 2017). As noted above, restoration can also be a tool to gain access to land or to displace people from their lands (Rai et al. 2018). Costs of FLR are often under-estimated (FAO and Global Mechanism of the UNCCD 2015) and benefits frequently skewed. For example, many intermediary organizations may receive funding for FLR, while local inhabitants may have to face more costs than benefits. Furthermore, while restoration may provide long term gains in terms of restored ecosystem services, short term losses are borne frequently by the most vulnerable (McElwee 2009). Decisions by distant stakeholders with no in-country legitimacy (Adams et al. 2014, Lerch 2014) are of concern as the global debate on FLR takes hold.

\section{Application to the Fandriana- Marolambo Landscape in Madagascar}

An understanding of stakeholders can help guide FLR project activities, leading to more targeted and relevant interventions. Figure 2 takes the elements proposed above and applies them to the Fandriana-Marolambo context. Starting from the left, the first column identifies the stakeholders and the second column situates them spatially. In the third column their discipline can be identified. The fourth column presents the sector with which they can best be associated. The next two columns present motivations for these stakeholder groups and different choices made because of power dynamics. Understanding all of these elements contributes to designing a series of actions (final column on the right) that are spatially appropriate, relevant to the discipline, take into account the sector and the motivations of each stakeholder group, as well as considering power aspects. For example, local communities were found to be 


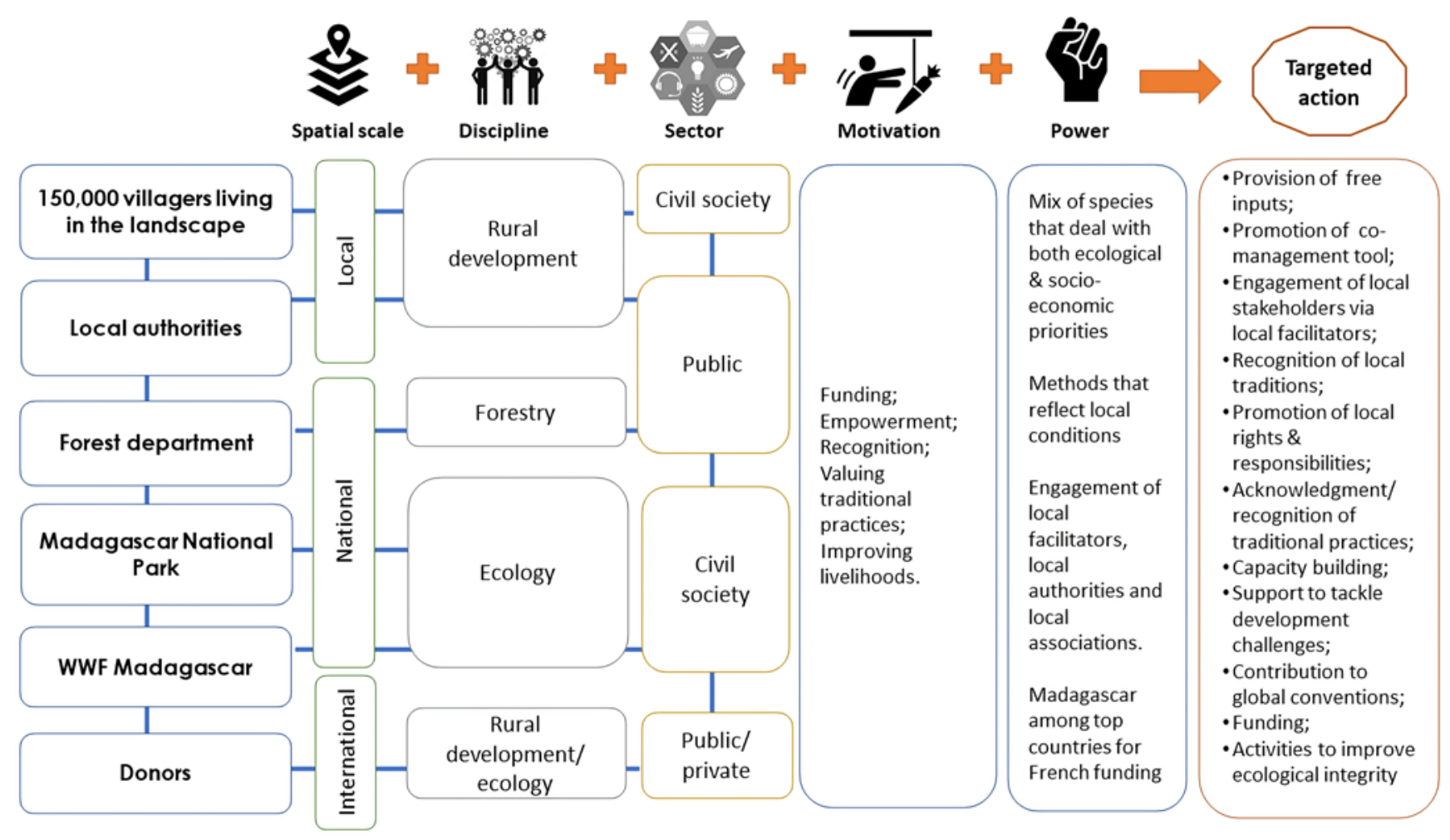

Figure 2. Translating an understanding of stakeholders into actions in the Fandriana-Marolambo FLR project in Madagascar.

strongly motivated by the officialization of co-management arrangements which granted them greater power in natural resource management. They were also more likely to engage in the FLR project when provided with free inputs, their traditions acknowledged, and local facilitators brought into the project. Capacity building responded to the needs of several stakeholders. Madagascar National Parks and WWF were strongly motivated by the restoration of ecological integrity and emphasized the use of indigenous species in restoration. The alignment between FLR and Madagascar's commitments to different conventions provided an incentive for the national government representatives (forest department) to engage in the project.

\section{Conclusion}

To better define FLR interventions it is important to understand stakeholders to engage them effectively. Stakeholders in FLR can be classified and understood in different ways depending on which sector they are from, the scale at which they are found, the discipline that influences them, and power dynamics that affect them. Understanding these divergences and the motivations of different disciplinary stakeholders can help to design more appropriate FLR strategies. Stakeholders are not static; groups will evolve, interact, and their relationship to the FLR process will also change over time. Furthermore, FLR is a long-term process, with scope for much adaptive management.
A better understanding of the sectors from which stakeholders originate helps to address the challenges of operational silos, competition for funding and find common ground. Integration across sectors is essential when dealing with large scale and long-term processes such as FLR (Mansourian and Parrotta 2018). At the same time, understanding the spatial scale within which stakeholders are found helps to identify inconsistencies across these scales that affect key stakeholders and how they relate to FLR, to define multiscalar strategies that recognize these challenges and ultimately seek flexibility across these scales. For FLR to be effective, while "engaging stakeholders" is often described as one of the first steps in the process, an understanding of stakeholder motivations is also needed to take "engagement" beyond meetings, and into a more in-depth analysis of potential positive and negative motivations for engaging (or not) in FLR. A more complete understanding of these motivations contributes to designing appropriate approaches and strategies, avert potential conflicts and negotiate more successfully. Finally, an understanding of power dynamics in FLR can help to address the risk of marginalization of certain groups, understand and compensate for the opportunity cost of FLR, and address distributional aspects.

As we enter the UN Decade on Ecosystem Restoration (2021-2030), it is important to not only understand who are key stakeholders in restoration, but also their relationship to each other and to the restoration process, 
motivations and underlying power dynamics. In this way, negotiations and trade-offs can be carried out in a transparent and fair manner, and power imbalances among stakeholders can be corrected. At a global level, further processes, systems, and capacity are urgently required to ensure that all stakeholders are effectively brought into FLR processes, can play a role, where relevant, in the FLR decision-making process, and when necessary, receive fair compensation. New tools and skills are needed to ensure a more refined analysis of stakeholder groups, their motivations and power relations, so as to effectively engage them in FLR and related large-scale forest restoration initiatives being widely promoted.

\section{Acknowledgments}

This paper comes out of a session on "Restoration by whom, for whom" at the Society for Ecological Restoration's global conference in Cape Town in September 2019. The session was organized by the CGIAR centers: the Alliance of Bioversity International and CIAT, the International Water Management Institute (IWMI), and the International Food Policy Research Institute (IFPRI), and was supported by the CGIAR Research Programs on Forests, Trees and Agroforestry (FTA); Water, Land and Ecosystems (WLE); and Policies Institutions and Markets (PIM). Funding for open access was provided by the CGIAR Research Programs on Forests, Trees and Agroforestry; Water, Land and Ecosystems; and Policies, Institutions, and Markets. I would like to thank Marlène Elias, Deepa Joshi and Ruth Meinzen-Dick for their input into an earlier draft, as well as two anonymous reviewers and the journal's editors.

\section{References}

Adams, C., S.T. Rodrigues, M. Calmon and C. Kumar. 2016. Impacts of large-scale forest restoration on socioeconomic status and local livelihoods: what we know and do not know. Biotropica 48:731-744.

Adams, W.M., I.D. Hodge and L. Sandbrook. 2014. New spaces for nature: the re-territorialisation of biodiversity conservation under neoliberalism in the UK. Transactions of the Institute of British Geographers 39:574-588.

Agrawal, A. and M.C. Lemos. 2007. A greener revolution in the making?: Environmental governance in the 21st century. Environment: Science and Policy for Sustainable Development 49: 36-45.

Akhtar-Schuster, M., L.C. Stringer, A. Erlewein, G. Metternicht, S. Minelli, U. Safriel, et al. 2017. Unpacking the concept of land degradation neutrality and addressing its operation through the Rio Conventions. Journal of Environmental Management 195:4-15.

Aronson, J., P.H. Brancalion, G. Durigan, R.R. Rodrigues, V.L. Engel, M. Tabarelli, et al. 2011. What role should government regulation play in ecological restoration? Ongoing debate in São Paulo State, Brazil. Restoration Ecology 19:690-695.

Auclair, L., A. Bourbouze, P. Dominguez and D. Genin. 2006. Les Agdals du Haut Atlas (Maroc) Biodiversité et Gestion Communautaire de l'accès Aux Ressources Forestières et Pastorales. Marseille, France: IRD.
Bäckstrand, K. and E. Lövbrand. 2006. Planting trees to mitigate climate change: Contested discourses of ecological modernization, green governmentality and civic environmentalism. Global Environmental Politics 6:50-75.

Bastin, J.F., Y. Finegold, C. Garcia, D. Mollicone, M. Rezende, D. Routh et al. 2019. The global tree restoration potential. Science 365(6448):76-79.

Besseau, P., S. Graham and T. Christophersen (eds), 2018. Restoring Forests and Landscapes: The Key to a Sustainable Future. Vienna, Austria: IUFRO.

Bixler, R.P., T. Jedd and C. Wyborn. 2018. Polycentric governance and forest landscape restoration: Considering local needs, knowledge types and democratic principles. Pages 176-197 in S. Mansourian and J. Parrotta (eds), Forest Landscape Restoration: Integrated Approaches to Support Effective Implementation. London, UK: Routledge.

Blom, B., T. Sunderland and D. Murdiyarso. 2010. Getting REDD to work locally: lessons learned from integrated conservation and development projects, Environmental Science and Policy 13:164-172.

Boedhihartono, A.K. and J. Sayer. 2012. Forest landscape restoration: restoring what and for whom? Pages 309-323 in J. Stanturf, D. Lamb and P. Madsen (eds), Forest Landscape Restoration. Dordrecht, The Netherlands: Springer.

Brancalion, P.H., A. Niamir, E. Broadbent, R. Crouzeilles, F.S. Barros, A.M.A., Zambrano, et al. 2019. Global restoration opportunities in tropical rainforest landscapes. Science Advances 5: eaav3223.

Brooks, T.M., R.A. Mittermeier, C.G. Mittermeier, G.A. Da Fonseca, A.B. Rylands, W.R. Konstant, et al. 2002. Habitat loss and extinction in the hotspots of biodiversity. Conservation Biology 16:909-923.

Buckingham, K., S. Ray, B. Arakwiye, A.G. Morales, R. Singh, D. Maneerattana et al. 2018. Mapping Social Landscapes: A Guide to Restoration Opportunities Mapping. World Resources Institute, Washington.

Carmenta, R. and B. Vira. 2018. 2 Integration for restoration. Pages 16-26 in S. Mansourian and J. Parrotta (eds), Forest Landscape Restoration: Integrated Approaches to Support Effective Implementation. London, UK: Routledge.

Cash, D.W., W.N. Adger, F. Berkes, P. Garden, L. Lebel, P. Olsson, et al. 2006. Scale and cross-scale dynamics: governance and information in a multilevel world. Ecology and Society 11:8.

Charnley, S. and M.R. Poe. 2007. Community forestry in theory and practice: Where are we now? Annual Review of Anthropology. 36:301-336.

Chazdon, R.L., P.H. Brancalion, D. Lamb, L. Laestadius, M. Calmon and C. Kumar. 2017. A policy-driven knowledge agenda for global forest and landscape restoration. Conservation Letters 10:125-132.

Ciccarese, L., A. Mattsson and D. Pettenella. 2012. Ecosystem services from forest restoration: thinking ahead. New Forests 43:543-560.

Clewell, A.F. and J. Aronson. 2006. Motivations for the restoration of ecosystems. Conservation Biology 20:420-428.

Cronkleton, P., Y. Artati, H. Baral, K. Paudyal, M.R. Banjane, J.L. Liu, et al. 2017. How do property rights reforms provide incentives for forest landscape restoration? Comparing evidence from Nepal, China and Ethiopia. International Forestry Review 19:8-23.

Crouzeilles, R., M. Curran, M.S. Ferreira, D.B. Lindenmayer, C.E. Grelle and J.M.R. Benayas. 2016. A global meta-analysis on the ecological drivers of forest restoration success. Nature Communications 7:1-8. 
Ekroos, J., J. Leventon, J. Fischer, J. Newig and H.G. Smith. 2017. Embedding evidence on conservation interventions within a context of multilevel governance. Conservation Letters 10: 139-145.

El-Gohary, N.M., H. Osman and T.E. El-Diraby. 2006. Stakeholder management for public private partnerships. International Journal of Project Management 24:595-604.

Enengel, B., A. Muhar, M. Penker, B. Freyer, S. Drlik and F. Ritter. 2012. Co-production of knowledge in transdisciplinary doctoral theses on landscape development-an analysis of actor roles and knowledge types in different research phases. Landscape and Urban Planning 105:106-117.

Erbaugh, J.T., N. Pradhan, J. Adams, J.A. Oldekop, A. Agrawal, D. Brockington, et al. 2020. Global forest restoration and the importance of prioritizing local communities. Nature Ecology \& Evolution 4:1472-1476.

FAO \& Global Mechanism of the UNCCD. 2015. Sustainable Financing for Forest and Landscape Restoration: Opportunities, Challenges and the Way Forward. Discussion paper. Rome.

Freeman, R.E. 1984. Strategic Management: A Stakeholder Approach. Boston, MA: Pitman.

Gann, G.D., T. McDonald, B. Walder, J. Aronson, C.R. Nelson, J. Jonson, et al. 2019. International principles and standards for the practice of ecological restoration. Restoration Ecology 27:S1-S46.

Grimble, R. and K. Wellard. 1997. Stakeholder methodologies in natural resource management: a review of principles, contexts, experiences and opportunities. Agricultural Systems 55:173-193.

Hagger V., J. Dwyer and K. Wilson. 2017. What motivates ecological restoration?. Restoration Ecology 25:832-843.

Höhl, M., V. Ahimbisibwe, J.A. Stanturf, P. Elsasser, M. Kleine and A. Bolte. 2020. Forest landscape restoration-What generates failure and success? Forests 11:938.

IPBES, 2018. Summary for policymakers of the thematic assessment report on land degradation and restoration of the Intergovernmental Science-Policy Platform on Biodiversity and Ecosystem Services. R. Scholes, L. Montanarella, A. Brainich, N. Barger, B. ten Brink, M. Cantele, et al. (eds.). Bonn: IPBES secretariat.

ITTO 2020. Guidelines for Forest Landscape Restoration in the Tropics. ITTO Policy Development Series No. 24. Yokohama: International Tropical Timber Organization (ITTO).

Kandel, M., G. Agaba, R.S. Alare, T. Addoah and K. Schreckenberg. 2021. Assessing social equity in farmer-managed natural regeneration (FMNR): Findings from northeastern Ghana. Ecological Restoration 39:64-76.

Kozar, R., L.E. Buck, E.G. Barrow, T.C.H. Sunderland, D.E. Catacutan, C. Planicka, et al. 2014. Toward Viable Landscape Governance Systems: What Works? Washington, DC: EcoAgriculture Partners, on behalf of the Landscapes for People, Food, and Nature Initiative.

Kröger, M. 2017. Inter-sectoral determinants of forest policy: the power of deforesting actors in post-2012 Brazil. Forest Policy and Economics 77:24-32.

Krott, M., A. Bader, C. Schusser, R. Devkota, A. Maryudi, L. Giessen, et al. 2014. Actor-centred power: The driving force in decentralised community based forest governance. Forest Policy and Economics 49:34-42.

Lake, F., J. Parrotta, C. Giardina, I. Hunt-Davidson and Y. Uprety. 2018. Integration of traditional and Western knowledge in forest landscape restoration. Pages 198-226 in S. Mansourian and J. Parrotta (eds), Forest Landscape Restoration: Integrated
Approaches to Support Effective Implementation. London, UK: Routledge.

Lerch, L. 2014. The geopolitics of land: population, security and territory viewed from the international financing of the land survey in Bolivia (1996-2013). Journal of Latin American Geography 13:137-168.

Liu, J., S. Li, Z. Ouyang, C. Tam and X. Chen. 2008. Ecological and socioeconomic effects of China's policies for ecosystem services. Proceedings of the National Academy of Sciences 105:9477-9482.

Lund, C., 2011. Fragmented sovereignty: land reform and dispossession in Laos. Journal of Peasant Studies 38:885-905.

Mansourian, S. 2018a. In the eye of the beholder: Reconciling interpretations of forest landscape restoration. Land Degradation and Development 29:2888-2898.

Mansourian, S. 2018b. Chapter 9-Stakeholders: Who decides what to restore, why and where? Pages $139-157$ in S. Mansourian and J. Parrotta (eds), Forest Landscape Restoration. London, UK: Routledge.

Mansourian, S. and D. Vallauri. 2014. Restoring forest landscapes: important lessons learnt. Environmental Management 53: 241-251.

Mansourian, S. and J. Parrotta. 2019. From addressing symptoms to tackling the illness: Reversing forest loss and degradation. Environmental Science and Policy. doi.org/10.1016/ j.envsci.2019.08.007.

Mansourian, S. and J. Parrotta (eds.). 2018. Forest Landscape Restoration: Integrated Approaches to Support Effective Implementation. London, UK: Routledge.

Mansourian, S., A. Razafimahatratra and D. Vallauri. 2018. Lessons Learnt From 13 Years of Restoration in a Moist Tropical Forest: The Fandriana-Marolambo Landscape in Madagascar. Paris: WWF France. wwf.panda.org.

Mansourian, S., A. Razafimahatratra, P. Ranjatson and G. Rambeloarisao. 2016. Novel governance for forest landscape restoration in Fandriana Marolambo, Madagascar. World Development Perspectives 3:28-31.

Mathur, V.N., A.D. Price, S.A. Austin and C. Moobela. 2007. Defining, identifying and mapping stakeholders in the assessment of urban sustainability. In M. Horner et al. (eds). Proceedings: SUE-MoT Conference 2007: International Conference on Whole Life Sustainability and its Assessment, Glasgow, Scotland, 27th29th June 2007.

McElwee, P., 2009. Reforesting 'bare hills' in Vietnam: Social and environmental consequences of the 5 million hectare reforestation program. Ambio 38:325-333.

McGinley, K., R. Alvarado, F. Cubbage, D. Diaz, P.J. Donoso, L.A. Gonçalves Jacovine, et al. 2012. Regulating the sustainability of forest management in the Americas: Cross-country comparisons of forest legislation. Forests 3:467-505.

Mitchell, R.K., B.R. Agle and D.J. Wood. 1997. Toward a theory of stakeholder identification and salience: Defining the principle of who and what really counts. Academy of Management Review 22:853-886.

Murcia, C., M.R. Guariguata, A. Andrade, G.I. Andrade, J. Aronson, E.M. Escobar, et al. 2016. Challenges and prospects for scalingup ecological restoration to meet international commitments: Colombia as a case study. Conservation Letters 9:213-220.

Nagendra, H., 2007. Drivers of reforestation in human-dominated forests. Proceedings of the National Academy of Sciences 104:15218-15223. 
Nutt, P. and R. Backoff. 1992. Strategic Management of Public and Third Sector Organizations: A Handbook for Leaders. San Francisco, CA: Jossey-Bass.

O'Farrell, P.J. and P.M. Anderson. 2010. Sustainable multifunctional landscapes: A review to implementation. Current Opinion in Environmental Sustainability 2:59-65.

Ostrom, E. 2010. Beyond markets and states: polycentric governance of complex economic systems. American Economic Review 100:641-72.

Phelps, J., E.L. Webb and A. Agrawal. 2010. Does REDD+ threaten to recentralize forest governance? Science 328:312-313.

Pinto, S.R., F. Melo, M. Tabarelli, A. Padovesi, C.A. Mesquita, C.A. de Mattos Scaramuzza, et al. 2014. Governing and delivering a biome-wide restoration initiative: The case of Atlantic Forest Restoration Pact in Brazil. Forests 5:2212-2229.

Poffenberger, M. 2006. People in the forest: community forestry experiences from Southeast Asia. International Journal of Environment and Sustainable Development 5:57-69.

Rai, N.D., S. Bhasme and P. Balaji. 2018. Power, inequality and rights: A political ecology of forest restoration. Pages 47-62 in S. Mansourian and J. Parrotta (eds), Forest Landscape Restoration: Integrated Approaches to Support Effective Implementation. London, UK: Routledge.

Reed, M.S., A. Graves, N. Dandy, H. Posthumus, K. Hubacek, J. Morris, et al. 2009. Who's in and why? A typology of stakeholder analysis methods for natural resource management. Journal of Environmental Management 90:1933-1949.

Reed, J., J. Van Vianen, E.L. Deakin, J. Barlow and T. Sunderland. 2016. Integrated landscape approaches to managing social and environmental issues in the tropics: learning from the past to guide the future. Global Change Biology 22:2540-2554.

Reinecke, S. and M. Blum. 2018. Discourses across scales on forest landscape restoration. Sustainability 10:613.

Roelens, J.B., D. Vallauri, A. Razafimahatratra, G. Rambeloarisoa and F.L. Razafy. 2010. Restauration des Paysages Forestiers: Cinq ans de Réalisation à Fandriana-Marolambo, Madagascar. Paris: WWF France.

Ruelle, M.L., K.A. Kassam and Z. Asfaw. 2017. Human ecology of sacred space: Church forests in the highlands of northwestern Ethiopia. Environmental Conservation 1-10.

Sayer, J., G. Bull and C. Elliott. 2008. Mediating forest transitions: 'Grand Design' or 'Muddling Through'. Conservation and Society 6:320-327.

Sayer, J., C. Margules, A.K. Boedhihartono and A. Dale. 2015. Landscape approaches; what are the pre-conditions for success? Sustainability Science 10:345.

Schweizer, D., P. Meli, P.H. Brancalion and M.R. Guariguata. 2019. Implementing forest landscape restoration in Latin America: Stakeholder perceptions on legal frameworks. Land Use Policy:104244.

Stanturf J.A., S. Mansourian, A. Darabant, M. Kleine, P. Kant, J. Burns et al. 2020. Forest Landscape Restoration Implementation: Lessons
Learned from Selected Landscapes in Africa, Asia and Latin America. Occasional Paper No. 33. Vienna, Austria: IUFRO.

Stanturf, J.A., B.J. Palik and R.K. Dumroese. 2014. Contemporary forest restoration: A review emphasizing function. Forest Ecology and Management 331:292-323.

Stanturf, J., S. Mansourian and M. Kleine (eds.) 2017. Implementing Forest Landscape Restoration: a Practitioner's Guide. Vienna: IUFRO.

SwissRe. 2016. Natural Catastrophes and Man-Made Disasters in 2015: Asia Suffers Substantial Losses. Zurich, Switzerland: SwissRe.

Vallauri, D., J. Aronson and N. Dudley. 2005. An attempt to develop a framework for restoration planning. Pages 63-70 in S. Mansourian, D. Vallauri and N. Dudley (eds), Forest Restoration in Landscapes: Beyond Planting Trees. New York, NY: Springer.

van Oosten, C., A. Uzamukunda and H. Runhaar. 2018. Strategies for achieving environmental policy integration at the landscape level. A framework illustrated with an analysis of landscape governance in Rwanda. Environmental Science \& Policy 83:63-70.

van Oosten, C., H. Runhaar and B. Arts. 2019. Capable to govern landscape restoration? Exploring landscape governance capabilities, based on literature and stakeholder perceptions. Land Use Policy: 104020.

Veldman, J.W., G.E. Overbeck, D. Negreiros, G. Mahy, S. Le Stradic, G.W. Fernandes, et al. 2015. Tyranny of trees in grassy biomes. Science 347:484-485.

Verdone, M. and A. Seidl. 2017. Time, space, place, and the Bonn Challenge global forest restoration target. Restoration Ecology 25:903-911.

Virapongse, A., 2017. Smallholders and forest landscape restoration in upland northern Thailand. International Forestry Review 19:102-119.

Weston, P., R. Hong, C. Kaboré and C.A. Kull. 2015. Farmer-managed natural regeneration enhances rural livelihoods in dryland West Africa. Environmental Management 55:1402-1417.

Wiegant, D., M. Peralvo, P. van Oel and A. Dewulf. 2020. Five scale challenges in Ecuadorian forest and landscape restoration governance. Land Use Policy 96:104686.

WWF and IUCN. 2000. Minutes of the forests reborn workshop in Segovia. Unpublished.

Zoomers, A. 2010. Globalisation and the foreignisation of space: seven processes driving the current global land grab. The Journal of Peasant Studies 37:429-447.

Stephanie Mansourian, Mansourian.org, University of Geneva, 36 Mont d'Eau du Milieu, 1276 Gingins, Switzerland,stephanie@mansourian.org. 